\begin{tabular}{|ll|}
\hline Received & $: 5$ September2019 \\
Revised & $: 7$ September 2019 \\
Accepted & $: 9$ September 2019 \\
Published & $: 27$ Desember 2019 \\
\hline
\end{tabular}

\title{
Implementation of Learning Models Numbered Head Together Through Tamansiswa Teachings Niteni, Niroke, Nambahi in the Written Indonesian Language Skills Course Elementary School Teacher Education Study Program
}

\author{
Siti Anafiah ${ }^{1, a)}$, Endang Hangestiningsih ${ }^{1, b)}$ \\ ${ }^{1}$ Universitas Sarjanawiyata Tamansiswa Yogyakarta, Indonesia

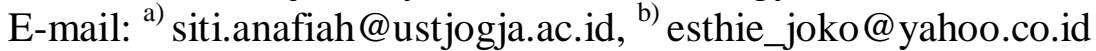

\begin{abstract}
This study aims to describe the implementation of the Numbered Head Together (NHT) learning model through the teaching of Niteni, Niroke, Nambahi (Tri N) teaching in the Indonesian Language Skills course in Writing at the PGSD Study Program at Sarjanawiyata Tamansiswa University in Yogyakarta. This type of research is qualitative research. The subject of research is S1 semester 3 students of PGSD FKIP UST. Data collection techniques using observation, interviews, and documentation. Data analysis techniques using an interactive model. The analysis consists of three activities, namely: data reduction, data presentation, and drawing conclusions / verification. The results of this study were obtained that the application of the NHT learning model through the teaching concept of Tamansiswa Tri $\mathrm{N}$ in the KBIT course is contained in the Semester Learning Plan (RPS) and the learning process. In Niteni activities, students listened to the material explanation from the lecturer and intensively read the articles provided. Niroke, students working on assignments in groups to analyze the contents of the article with the formula $5 \mathrm{~W}+1 \mathrm{H}$, the language and writing in accordance with the material that has been explained by the lecturer. Nambahi, one of the group representatives who had been appointed by the lecturer based on the number that was given to present the results of the discussion with the language and knowledge they have.
\end{abstract}

Keywords: numbered head together, tri N, written Indonesian language skills 


\section{Abstrak}

Penelitian ini bertujuan untuk mendeskripsikan implementasi model pembelajaran Numbered Head Together (NHT) melalui ajaran tamansiswa Niteni, Niroke, Nambahi (Tri N) dalam mata kuliah Keterampilan Berbahasa Indonesia Tulis di Prodi PGSD Universitas Sarjanawiyata Tamansiswa Yogyakarta. Jenis penelitian ini adalah penelitian kualitatif. Subjek penelitian mahasiswa S1 semester 3 PGSD FKIP UST. Teknik pengumpulan data menggunakan observasi, wawancara, dan dokumentasi. Teknik analisis data menggunakan model interaktif. Analisis tersebut terdiri atas tiga alur kegiatan, yaitu: reduksi data, penyajian data, dan penarikan kesimpulan/verifikasi. Hasil penelitian ini diperoleh bahwa penerapan model pembelajaran NHT melalui konsep ajaran Tamansiswa Tri N dalam mata kuliah KBIT terdapat dalam Rencana Pembelajaran Semester (RPS) dan proses pembelajarannya. Dalam kegiatan Niteni, mahasiswa menyimak penjelasan materi dari dosen dan membaca secara intensif artikel yang diberikan. Niroke, mahasiswa mengerjakan tugas secara berkelompok menganalisis isi artikel dengan rumus $5 \mathrm{~W}+1 \mathrm{H}$, bahasa dan tata tulisnya sesuai dengan materi yang sudah dijelaskan oleh dosen. Nambahi, salah satu perwakilan kelompok yang sudah ditunjuk oleh dosen berdasarkan nomor yang sudah diberikan untuk mempresentasikan hasil diskusi dengan bahasa dan pengetahuan yang dimilikinya.

Kata kunci: numbered head together, tri N, keterampian berbahasa Indonesia tulis

\section{PENDAHULUAN}

Undang-undang Nomor 20 Tahun 2003 tentang sistem pendidikan nasional menyebutkan bahwa pendidikan nasional berfungsi mengembangkan kemampuan dan membentuk watak serta peradaban bangsa yang bermartabat dalam rangka mencerdaskan kehidupan bangsa. Pendidikan bertujuan untuk mengembangkan potensi peserta didik/ mahasiswa agar menjadi manusia memiliki kekuatan spiritual keagamaan, pengendalian diri, berakhlak mulia, serta kreatif, dan menjadi warga negara yang demokratis.

Pendidikan adalah salah satu bentuk perwujudan kebudayaan manusia yang dinamis sarat perkembangan. Oleh karena itu, perubahan dan perkembangan pendidikan harus sejalan dengan perubahan kebudayaan. Dalam pembelajaran, dosen juga harus melakukan perubahan dan perkembangan dalam mengajar peserta didiknya, termasuk dalam mengajar mata kuliah Keterampilan Berbahasa Indonesia Tulis (KBIT). Pendidikan nasional menurut paham Taman Siswa ialah pendidikan yang beralaskan garis- hidup dari bangsanya (Cultureel-National) dan ditujukan untuk keperluan perikehidupan yang dapat mengangkat derajat Negara dan rakyatnya, agar dapat bekerja bersama-sama dengan lain-lain bangsa untuk kemuliaan segenap manusia diseluruh dunia (Majelis Luhur Tamansiswa).

Mata kuliah KBIT merupakan salah satu mata kuliah yang berada di semester 3 Program Studi Pendidikan Guru Sekolah Dasar, Universitas Sarjanawiyata Tamansiswa. 
Mata kuliah ini terdiri atas keterampilan membaca dan menulis. Kedua keterampilan ini yang kadang dirasa sulit oleh mahasiswa. Dalam keterampilan membaca biasanya mahasiswa merasa malas dan sulit untuk menemukan ide gagasan dalam bacaan yang dibacanya. Begitu pula dalam keterampilan menulis, biasaya mahasiswa sulit untuk menuangkan ide gagasannya dalam bentuk tulis.

Slameto (2010) menyatakan belajar merupakan suatu proses usaha yang dilakukan seseorang untuk memperoleh suatu perubahan tingkah laku yang baru secara keseluruhan, sebagai hasil pengalamannya sendiri dalam interaksi dengan lingkungannya”. Untuk mendapatkan sesuatu seseorang harus melakukan usaha agar apa yang di inginkan dapat tercapai. Usaha tersebut dapat berupa kerja mandiri maupun kelompok dalam suatu interaksi. Hasil belajar merupakan bagian terpenting dalam pembelajaran.

Syah (2006) mengatakan bahwa prestasi belajar merupakan taraf keberhasilan sebuah proses belajar-mengajar (the teaching learning process) atau taraf keberhasilan sebuah program pembelajaran atau penyajian materi, dan kenaikan kelas. Sedangakan menurut Sumadi Suryabrata (2013:296-297) prestasi belajar merupakan hasil yang dicapai oleh seseorang dalam usaha belajar sebagaimana yang dinyatakan dalam raport.

Sudjana (2009) mendefinisikan hasil belajar siswa pada hakikatnya adalah perubahan tingkah laku sebagai hasil belajar dalam pengertian yang lebih luas mencakup bidang kognitif, afektif, dan psikomotorik. Menurut Kunandar (2009), hasil belajar adalah kemampuan siswa dalam memenuhi tahapan pencapaian pengalaman belajar dalam suatu kompetensi dasar. Hasil belajar bisa berbentuk pengetahuan, keterampilan maupun sikap. Kemampuan yang dimiliki siswa setelah menerima pengalaman belajar. Hasil belajar tampak sebagai terjadinya perubahan tingkah laku pada diri siswa, yang dapat diamati dan diukur dalam bentuk perubahan pengetahuan, sikap dan keterampilan (Hamalik, 2007).

Salah satu alternatif yang bisa menjadi pilihan utama untuk mengatasi permasalahan di atas adalah dosen harus mampu menerapkan konsep pembelajaran yang dapat melibatkan dan memotivasi mahasiswa sehingga dapat aktif, mudah dalam menuangkan ide gagasannya, tidak malas, dan tidak menganggap mata kuliah KBIT itu sulit, yaitu menggunakan model pembelajaran Numbered Head Together (NHT). Arends dalam Asma (2006) mengungkapkan model pembelajaran kooperatif dikembangkan untuk mencapai setidak-tidaknya tiga tujuan pembelajaran penting. Adapun tujuan pertama pembelajaran kooperatif, yaitu meningkatkan hasil akademik, dengan meningkatkan kinerja siswa dalam tugas- tugas akademiknya. Siswa yang lebih mampu akan menjadi narasumber bagi siswa yang kurang mampu, yang memiliki orientasi dan bahasa yang sama. Dalam penelitian ini, penulis memilih model pembelajaran Numbered Head Together (NHT) dengan pendekatan konsep pembelajaran Tri N (Niteni, Nirokke, Nambahi). 
NHT merupakan model pembelajaran inovatif yang dapat berpusat pada peserta didik. Numbered Head Together (NHT) sebagai salah satu tipe dari Model Pembelajaran Kooperatif dirancang sebagai salah satu alternatif pengganti terhadap struktur kelas tradisional. Miftahul (2012) menyatakan bahwa "Pada umumnya NHT (Numbered Heads Together) digunakan untuk melibatkan peserta didik dalam penguatan pemahaman pembelajaran atau mengetahui pemahaman peserta didik terhadap materi pembelajaran”. Menurut Miftahul (2012) langkah-langkah penerapan Model Pembelajaran Kooperatif Tipe Numbered Head Together (NHT) adalah sebagai berikut. 1) Siswa dibagi dalam kelompok-kelompok. Masing-masing siswa dalam kelompok diberi nomor. 2) Guru memberikan tugas/ pertanyaan dan masing-masing kelompok mengerjakannya. 3) Kelompok berdiskusi untuk menemukan jawaban yang dianggap paling benar dan memastikan semua anggota kelompok mengetahui jawaban tersebut. 4) Guru memanggil salah satu nomor. Siswa dengan nomor yang dipanggil mempresentasikan jawaban hasil diskusi kelompok mereka.

Tri N terdiri atas Niteni, Niroke, dan Nambahi yaitu untuk mempelajari segala sesuatu bisa ditempuh dengan cara "mengenali dan mengingat" sesuatu yang dipelajari (niteni), menirukan sesuatu yang dipelajari (nirokke), serta mengembangkan sustau yang dipelajari (nambahi) (Tim Dosen Ketamansiswaan, 2014: 39). Suroso (2011) pada artikelnya yang berjudul Pemikiran Ki Hajar Dewantara Tentang Belajar dan Pembelajaran menyatakan bahwa salah satu prinsip belajar yang dikemukakan Ki Hajar Dewantara adalah Tri N, yang merupakan singkatan dari Niteni, Niroke, dan Nambahi. Ketiga prinsip tersebut harus dilaksanakan secara berurutan, agar prinsip Tri $\mathrm{N}$ tersebut dapat diterapkan secara baik. Konsep pembelajaran Tri N (Niteni, Nirokke, Nambahi) adalah Niteni berarti memperhatikan, mengamati, atau menyimak. Dalam hal ini, mahasiswa memperhatikan, melakukan pengamatan, membaca atau mendengarkan dengan teliti, meraba, merasakan dengan pancainderanya. Niroke atau niruaken berarti meniru. Mahasiswa mencontoh, menirukan, melakukan sesuatu yang sama dengan hal atau sesuatu yang diamati. Nambahi berarti menambahkan. Mahasiswa berusaha menambah, menyesuaikan, melakukan perubahan, atau mengurangi model yang ditiru sesuai dengan kreativitas masing-masing.

Konsep Tri N (Niteni, Niroke, dan Nambahi) dapat diterapkan demi kemajuan pendidikan Indonesia dan kemajuan berbagai bidang lainnya. Dengan adanya konsep Tri N (Niteni, Nirokke, Nambahi) diharapkan dapat meningkatkan pemahaman, penguasaan konsep-konsep keterampilan berbahasa tulis, serta dapat menerapkannya sehingga mahasiswa lebih aktif dan proses pembelajaran menjadi lebih efektif. dengan demikian pembelajaran dengan konsep Tri N (Niteni, Nirokke, Nambahi) dapat meningkatkan motivasi mahasiswa dengan berpikir kreatif.

Tujuan dari penelitian ini untuk mendeskripsikan implementasi model pembelajaran NHT melalui ajaran Tamansiswa niteni, niroke, nambahi dalam mata 
kuliah Keterampilan Berbahasa Indonesia Tulis di Program Studi PGSD Universitas Sarjanawiyata Tamansiswa Yogyakarta.

\section{METODE PENELITIAN}

Jenis penelitian ini termasuk penelitian kualitatif. Moleong (2014) menyatakan bahwa penelitian kualitatif adalah penelitian yang bermaksud untuk memahami fenomena tentang apa yang dialami oleh subjek penelitian (contohnya perilaku, persepsi, dan lain sebagainya) secara holistik, dan dengan cara deskripsi dalam bentuk kata-kata dan bahasa, pada suatu konteks khusus yang alami dan dengan memanfaatkan berbagai metode alamiah.

Setting penelitian ini adalah Mahasiswa S1 Prodi PGSD FKIP UST. Teknik pengumpulan data penelitian ini menggunakan observasi berperan serta (participant observation), wawancara, dan dokumentasi. Analisis data dalam penelitian ini menggunakan analisis data model interaktif. Analisis tersebut terdiri atas tiga alur kegiatan yang terjadi secara bersamaan, yaitu: reduksi data, penyajian data, dan penarikan kesimpulan/verifikasi. Teknik yang digunakan untuk menetapkan keabsahan data pada kriteria derajat keterpercayaan (credibility) melalui ketekunan pengamatan dan triangulasi.

\section{HASIL DAN PEMBAHASAN}

Konsep ajaran Ki Hadjar Dewantara Niteni, Niroke, Nambahi terimplementasi dalam mata kuliah KBIT di Prodi PGSD FKIP UST. Penerapan tersebut tidak hanya terdapat dalam proses perkuliahan tetapi juga tertuang dalam Rencana Pembelajaran Semester (RPS). Kemampuan akhir yang diharapkan pada mata kuliah KBIT yang menunjukkan kerja mandiri dengan proses Tri N. Adapun implementasi ajaran KHD tertuang dalam RPS mata kuliah KBIT sebagai berikut.

\begin{tabular}{|c|c|c|c|c|c|c|c|c|c|}
\hline \multirow{2}{*}{$\begin{array}{l}\text { Minggu } \\
\text { ke- }\end{array}$} & \multirow{2}{*}{$\begin{array}{l}\text { Kemampuan } \\
\text { Akhir yang } \\
\text { diharapkan }\end{array}$} & \multirow[b]{2}{*}{ Bahan Kajian } & \multirow{2}{*}{$\begin{array}{c}\text { Metode } \\
\text { Pembelajaran }\end{array}$} & \multirow{2}{*}{$\begin{array}{c}\text { Media } \\
\text { Pembelajaran }\end{array}$} & \multirow{2}{*}{$\begin{array}{l}\text { Waktu } \\
\text { (menit) }\end{array}$} & \multirow{2}{*}{$\begin{array}{c}\text { Pengalaman } \\
\text { Belajar } \\
\text { Mahasiswa }\end{array}$} & \multicolumn{2}{|c|}{ Assesmen } & \multirow[b]{2}{*}{ Bobot } \\
\hline & & & & & & & Kriteria & Bentuk & \\
\hline 1 & 2 & 3 & 4 & 5 & 6 & 7 & 8 & 9 & 10 \\
\hline 7 & $\begin{array}{l}\text { 1. Menganalis } \\
\text { is artikel } \\
\text { surat kabar } \\
\text { 2. Menunjukk } \\
\text { an kerja } \\
\text { mandiri } \\
\text { dengan } \\
\text { proses Tri } \\
\text { N dan } \\
\text { TriNga. }\end{array}$ & $\begin{array}{l}\text { Analisis artikel } \\
\text { surat kabar }\end{array}$ & \begin{tabular}{|l|} 
Diskusi, tanya \\
jawab, dan \\
penugasan
\end{tabular} & $\begin{array}{l}\text { Artikel surat } \\
\text { kabar dan } \\
\text { power point }\end{array}$ & $2 \times 50$ & $\begin{array}{l}\text { 1. Mahasiswa } \\
\text { membaca } \\
\text { artikel surat } \\
\text { kabar tentang } \\
\text { pendidikan } \\
\text { dasar yang } \\
\text { telah } \\
\text { dipersiapkan } \\
\text { nya. } \\
\text { 2. Mahasiswa } \\
\text { memberikan } \\
\text { pendapatnya } \\
\text { mengenai isi } \\
\text { artikel. } \\
\text { 3. Mahasiswa } \\
\text { melakukan } \\
\text { refleksi } \\
\text { pembelajaran } \\
\text { dengan } \\
\text { bimbingan } \\
\text { dosen. }\end{array}$ & $\begin{array}{l}\text { Ketepatan dalam } \\
\text { melakukan } \\
\text { praktik } \\
\text { membaca } \\
\text { intensif artikel } \\
\text { surat kabar }\end{array}$ & \begin{tabular}{|l|} 
Tes tulis \\
Partisipasi
\end{tabular} & $5 \%$ \\
\hline
\end{tabular}


Penerapan ajaran KHD niteni, niroke, dan nambahi terdapat juga dalam pelaksanaan pembelajaran. Dalam Niteni mahasiswa menyimak penjelasan dari dosen terkait dengan materi jenis membaca dan menganalisis isi bacaan.

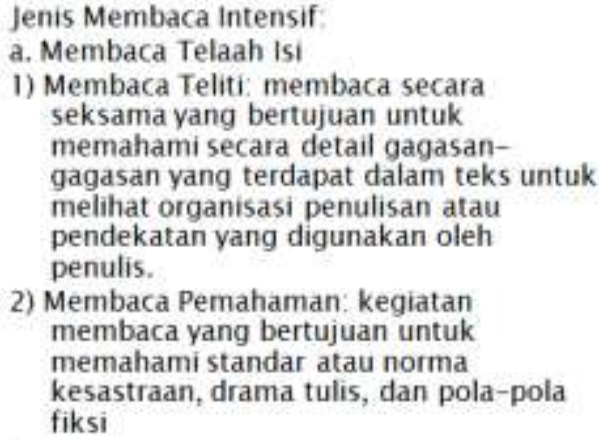

2) Membaca Pemahaman: kegiatan membaca yang bertujuan untuk

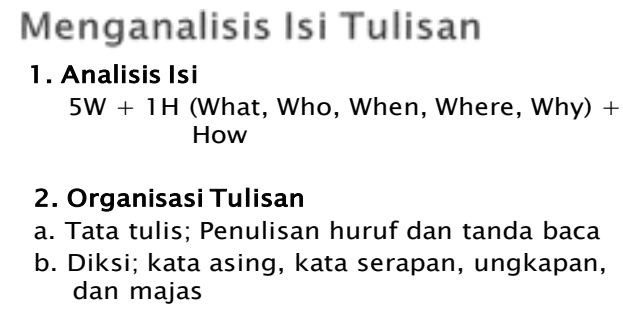

Dalam menyimak penjelasan dosen, mahasiswa diharapkan niteni yakni memahami dan mengingat secara mendalam materi yang disampaikan. Dalam proses niteni, mahasiswa menyimak sekaligus memahami materi jenis menyimak dan menganalisis isi bacaan dengan rumus $5 \mathrm{~W}+1 \mathrm{H}$ yang disampaikan oleh dosen. Menurut Effendy (1993: 186) dalam jurnalistik dikenal rumus "5W dan 1H". Rumus 5W dan $1 \mathrm{H}$ itu ialah, What, Who, Where, When, Why, dan How. Rumus tersebut menjadi syarat press release. Press-release harus mengandung hal-hal yang merupakan jawaban dari pertanyaan: Apa? (yang terjadi), Siapa? (yang terlibat dalam kejadian), Dimana? (terjadinya), Kapan? (terjadinya), mengapa? (terjadi demikian), dan Bagaimana? (terjadinya). Untuk mengetahui pemahaman mahasiswa tentang materi yang disimaknya, dosen memberikan umpan balik berupa pertanyaan. Setelah itu mahasiswa diminta untuk membaca artikel secara berkelompok.

Dalam pembelajaran KBIT ini, dosen menggunakan model pembelajaran Numbered Head Together (NHT) yakni model yang mengutamakan keaktifan mahasiswa. Mahasiswa dibagi menjadi beberapa kelompok, dosen memberikan tugas membaca dan mengidentifikasi isi artikel beserta nomor pada masing-masing anggota kelompok, mahasiswa mendiskusikan materi, dan selanjutnya dosen menunjuk salah satu nomor mahasiswa dalam kelompok untuk mempresentasikan hasil diskusi. 


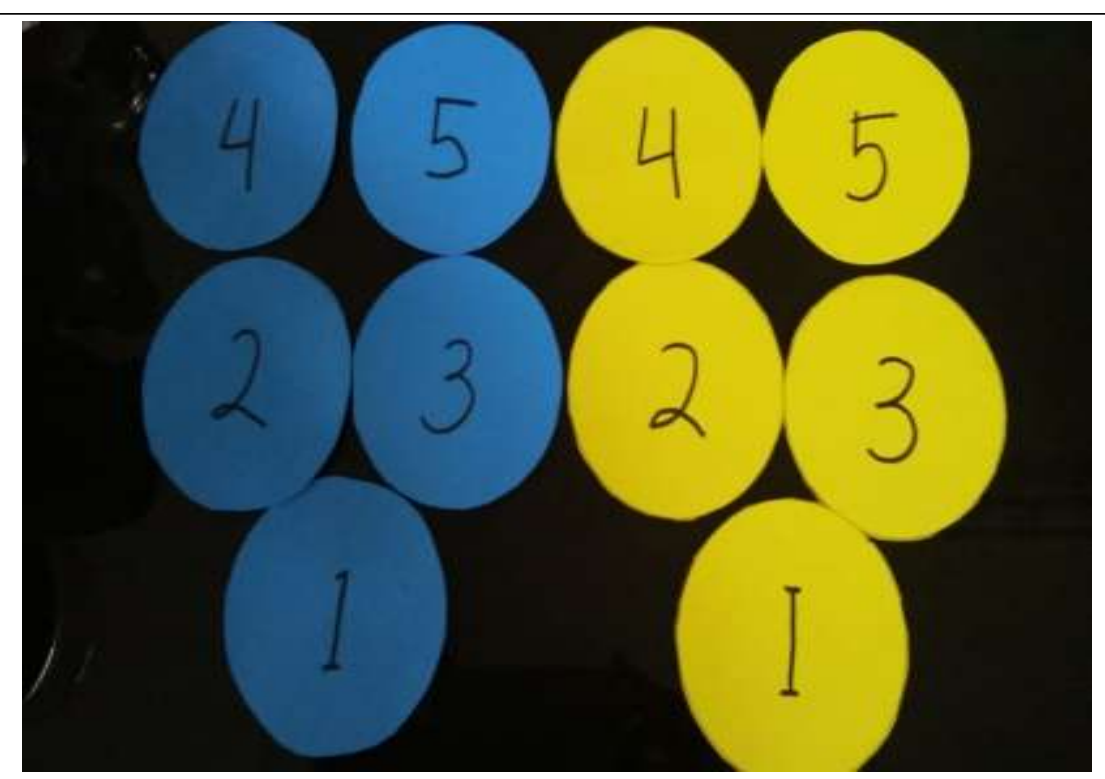

Setelah niteni, mahasiswa diminta untuk niroke yakni mengerjakan tugas sesuai dengan penjelasan yang sudah diterima secara berkelompok, sehingga ada kerjasama saling tolong menolong antarmahasiswa di kelompok tersebut. Dalam kegiatan niroke mahasiswa mendiskusikan tugas yang diberikan yakni menganalisis artikel surat kabar. Di dalam kegiatan menganalisis surat kabar, mahasiswa membaca secara intensif artikel surat kabar yang diberikan oleh dosen. Mahasiswa menganalisis dengan rumus $5 \mathrm{~W}+1 \mathrm{H}$ serta menganalisis bahasa dan tata tulis dalam artikel tersebut. Berikut ini hasil kerja mahasiswa secara kelompok.
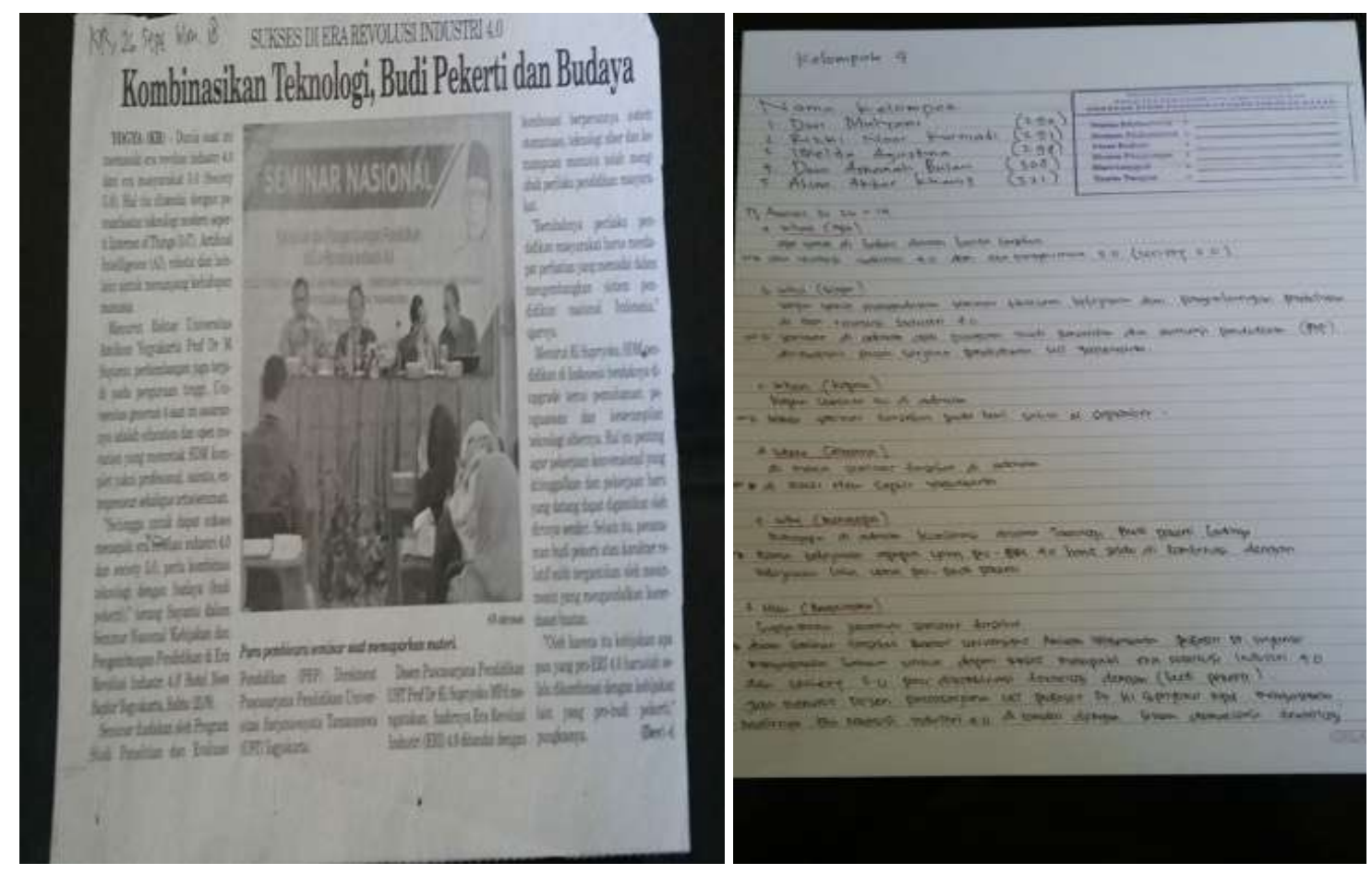

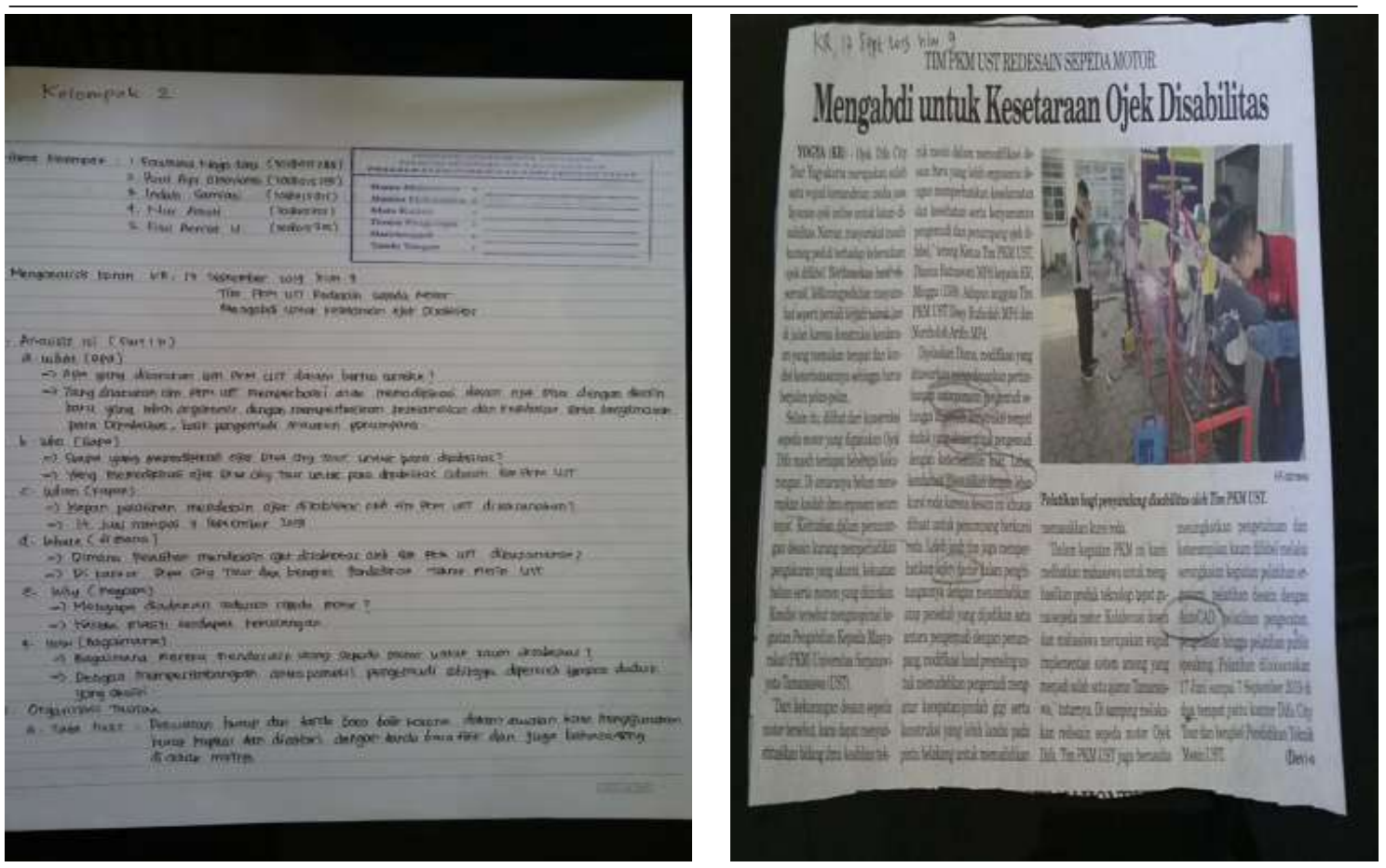

Nambahi, dalam kegiatan nambahi mahasiswa mempresentasikan hasil diskusi yang sudah dilakukan. Dalam kegiatan mempresentasikan, dosen akan menunjuk salah satu nomor yang dipegang mahasiswa dalam kelompok tersebut untuk maju. Dalam kegiatan tersebut mahasiswa harus memahami hasil diskusi, serta dapat menambahkan ide gagasan dan pengetahuannya dengan menggunakan pilihan bahasa mereka sendiri. Melalui konsep pembelajaran Tri N (Niteni, Niroke, Nambahi), siswa diarahkan untuk dapat melatih kemampuan semua panca inderanya dalam pembelajaran. Latihan panca indera itu dilakukan dalam setiap langkah pada kosep Tri $\mathrm{N}$, yaitu niteni, atau pengamatan yang melatih indera penglihatan, pendengaran, peraba, perasa, bahkan penciuman. Nirokke menuntut siswa memadukan persepsi-persepsi baru penggabungan persepsi yang ada daam dirinya. Nambahi menuntut siswa membuat kreasi baru dalam menyelesaikan permasalahan yang telah disampaikan agar dapt mudah dipahami ketika mempelajarinya kembali (Rozak, 2014).

\section{KESIMPULAN}

Dari hasil dan pembahasan penelitian di atas dapat disimpulkan sebagai berikut. Penerapan model pembelajaran NHT melalui konsep ajaran Tamansiswa Tri N di mata kuliah KBIT Prodi PGSD UST terintegrasi dalam RPS dan proses pembelajaran. Dalam RPS terdapat dalam kemampuan akhir yang diharapkan, metode, dan media pembelajaran. Dalam prose pembelajaran, niteni terletak pada kegiatan menyimak penjelasan dosen dan membaca artikel untuk mengidentifikasi isi bacaan melalui rumus $5 \mathrm{~W}+1 \mathrm{H}$. Niroke, mahasiswa mengerjakan tugas sesuai dengan materi yang sudah disimaknya. Nambahi, setelah mahasiswa berdiskusi kelompok, dosen memanggil salah satu nomor mahasiswa untuk mempresentasikan hasil diskusi.

Model pembelajaran inovatif perlu dilakukan oleh guru dalam memberikan materi, sehingga pembelajaran lebih menyenangkan dan mudah dipahami oleh siswa. 
Selain itu, penerapan konsep Tri N oleh Ki Hadjar Dewantara sangat penting dalam pelaksanaan pembelajaran, melalui niteni, niroke, dan nambahi.

\section{REFERENSI}

Asma, N. (2006). Model Pembelajaran Kooperatif. Jakarta. Departemen Pendidikan Nasional Direktorat Jenderal Pendidikan Tinggi.

Effendy, O. U. (1993). Human Relation dan Public Relation. Bandung: Mandar Maju.

Ipung, K. Y. (2014). “Niteni, Niroke, Nambahi sebagai Proses Berpikir Kreatif.” Jurnal Seni Rupa (Vol. 2 Nomor 2). hlm. 128-129.

Majelis Luhur Tamansiswa. (2013). Ki Hadjar Dewantara: Bagian Pertama (Pendidikan). Yogyakarta: UST-Press.

Miftahul, H. (2012). Coorperative Learning: Metode, Teknik, Struktur dan Model Terapan. Yogyakarta: Pustaka Belajar.

Moleong, L. (2014). Metodologi Penelitian Kualitatif. Bandung: Rosdakarya.

Oemar, H. (2007). Proses Belajar Mengajar. Jakarta. Bumi Aksara.

Purwahida, R. (2018). Problematika Pengembangan Modul Pembelajaran Baca Tulis Anak Usia Sekolah Dasar. Aksis: Jurnal Pendidikan Bahasa dan Sastra Indonesia 2(1). 118-134. doi: doi.org/10.21009/AKSIS.020108

Rozak, A. \& Wardina. (2014). Pengaruh Teknik 3N (Niteni, Nirokke, Nambahi) Ki Hadjar Dewantara terhadap Kemampuan Menulis Narasi Siswa. Cirebon: Arsip Respository FKIP Unswagati.

Slameto. (2010). Belajar dan Faktor-Faktor yang Mempengaruhinya. Jakarta. Rineka Cipta.

Sudjana, N. (2009). Penilain Hasil Proses Belajar Mengajar. Bandung. Remaja Rosdakarya.

Syah, M. (2016). Psikologi Pendidikan dengan Pendekatan Baru. Bandung: PT Remaja Rosdakarya.

Suroso. (2011). Pemikiran Ki Hadjar Dewantara Tentang Belajar dan Pembelajaran. Salatiga: Scholaria Jurnal Pendidikan dan Kebudayaan. Vol.1 No.1. Mei 2011: 46-72.

Tim Dosen Ketamansiswaan. (2014). Materi Kuliah Ketamansiswaan. Yogyakarta: UST Press. 